\title{
Is the detection of Mycobacterium tuberculosis DNA by ligase chain reaction worth the cost: experiences from an inner London teaching hospital
}

\author{
N Shetty, M Shemko, J Holton, G M Scott
}

\begin{abstract}
Aims-To evaluate the clinical usefulness and the costs of using a rapid, commercial ligase chain reaction test (LCx) to detect Mycobacterium tuberculosis directly from clinical samples.

Methods-A prospective study of 2120 routine clinical specimens from 1161 patients over a 13 month period. Investigations for mycobacterial disease by microscopy, culture, and the Abbott LCx assay were performed. Sequential LCx assays were monitored in a cohort of patients undergoing treatment. The costs of the assay were calculated using the WELCAN system. Sensitivity, specificity, and positive and negative predictive values of the $L C x$ assay were compared with conventional tests. The performance of the assay in patients undergoing treatment and cost in terms of WELCAN units converted to pounds/annum was studied. Results-The assay was $85 \% / 88 \%$ sensitive and $98 \% / 100 \%$ specific in culture confirmed/clinically confirmed cases of tuberculosis, respectively. The assay was not useful for the measurement of treatment outcomes. The test cost approximately $£ 42$ 500/annum.

Conclusions-The assay is a rapid, sensitive, and specific adjunct to clinical diagnosis, especially in differentiating nontuberculous mycobacteria. However, it does not differentiate old and treated tuberculosis from reactivated disease, it is not useful to monitor adherence to treatment, and it is expensive. (F Clin Pathol 2000;53:924-928)
\end{abstract}

Keywords: tuberculosis; diagnosis; ligase chain reaction

Department of Clinical Microbiology,

University College

London Hospitals and

PHLS Collaborating

Centre, Cecil

Flemming House,

Grafton Way, London

WC1E 6DB, UK

N Shetty

M Shemko

J Holton

G M Scott

Correspondence to: Dr Shetty

nandini.shetty@uclh.org

Accepted for publication 13 June 2000
One third of the world's population is infected with Mycobacterium tuberculosis. Active disease develops in eight to 10 million people/year, three million of whom die, making it the leading infectious cause of death in the world. ${ }^{1-3}$ Notification rates for tuberculosis continue to rise in London, with some inner London boroughs experiencing three to 10 times the national notification rate. ${ }^{4}$ Social deprivation, homelessness, immigration, the AIDS epidemic, and the failure of tuberculosis control all play a part in this increase. ${ }^{5}$

Tuberculosis control without improvements in socioeconomic conditions relies on case finding and chemotherapy. ${ }^{6}$ Delays in diagnosis and failure to isolate cases have been impli- cated in the transmission of tuberculosis in the health care setting. ${ }^{7}$ Serious hospital outbreaks of tuberculosis have occurred in wards with immunosuppressed patients. ${ }^{9}$ Clinical diagnosis is confirmed by microscopy and culture. Microscopy for acid fast bacilli is simple and rapid but is not sensitive and does not differentiate between $M$ tuberculosis and other species, such as Mycobacterium avium complex (MAC). Culture is specific and more sensitive but takes several weeks. Rapid differentiation between the mycobacterium species is important for treatment and infection control.

To speed up the process of the specific identification of mycobacteria, new methods based on DNA amplification have been developed. Polymerase chain reaction (PCR) based methods are rapid and sensitive ${ }^{10}$; however, they are labour intensive and require special facilities to prevent laboratory contamination. In house assays vary widely in their specificity and sensitivity. ${ }^{11}{ }^{12}$ The LCx $M$ tuberculosis assay (Abbott Laboratories, Diagnostic Division, Chicago, Illinois, USA) is based on the ligase chain reaction and is the first commercial, semiautomated nucleic acid amplification test method developed for use in the routine diagnostic laboratory for the direct detection of $M$ tuberculosis DNA from respiratory specimens. ${ }^{13} 14$ The aim of our study was to compare the performance of the assay with conventional methods in a busy diagnostic laboratory, serving a population with a relatively high risk of tuberculosis. ${ }^{15}$ In addition, we studied the clinical usefulness of the LCx assay, compared with smear and culture, in specimens collected sequentially over a period after onset of treatment from 15 patients with confirmed tuberculosis.

The cost of the assay was calculated in terms of WELCAN units. ${ }^{16}$ We present the cost implication of such a test during one year's unrestricted use.

\section{Materials and methods}

Routine clinical specimens submitted to the laboratory for investigation of mycobacterial disease from December 1997 to December 1998 were studied prospectively. The LCx assay was done in parallel with auramine smear examination and culture on Lowenstein-Jensen medium. All specimens other than urine and cerebrospinal fluid (CSF) were processed by the $N$-acetyl-L-cysteine- $\mathrm{NaOH}$ digestion/ decontamination procedure, ${ }^{17}$ before carrying out the LCx assay, smear, and culture. Cultures were held at $35^{\circ} \mathrm{C}$ for 12 weeks. All positive 
Table 1 Evaluation of the ligase chain reaction ( $L C x$ ) assay in culture confirmed Mycobacterium tuberculosis infection

\begin{tabular}{|c|c|c|c|c|c|c|c|c|}
\hline \multirow[b]{2}{*}{ Specimens (no.) } & \multicolumn{2}{|c|}{$\begin{array}{l}\text { Culture positive for } \\
\text { M tuberculosis }(n=131)\end{array}$} & \multicolumn{2}{|c|}{$\begin{array}{l}\text { Culture negative for } \\
\text { M tuberculosis }(n=1989)\end{array}$} & \multirow[b]{2}{*}{$\begin{array}{l}\text { Sensitivity } \\
(\%)\end{array}$} & \multirow[b]{2}{*}{$\begin{array}{l}\text { Specificity } \\
(\%)\end{array}$} & \multirow[b]{2}{*}{$\begin{array}{l}P P V \\
(\%)\end{array}$} & \multirow[b]{2}{*}{$\begin{array}{l}N P V \\
(\%)\end{array}$} \\
\hline & $\begin{array}{l}\text { LCx } \\
\text { positive }\end{array}$ & $\begin{array}{l}L C x \\
\text { negative }\end{array}$ & $\begin{array}{l}L C x \\
\text { positive }\end{array}$ & $\begin{array}{l}\text { LCx } \\
\text { negative }\end{array}$ & & & & \\
\hline All (2120) & 109 & 22 & 33 & $1956^{\star}$ & 85.6 & 98.4 & 79.9 & 98.9 \\
\hline Smear positive (114) & 91 & 1 & 7 & $15^{\star \star}$ & 98.9 & 75.9 & 92.9 & 95.7 \\
\hline Smear negative (2006) & 18 & 21 & 26 & 1941 & 65.0 & 98.7 & 60.0 & 98.9 \\
\hline Respiratory (2058) & 91 & 21 & 33 & 1913 & 84.2 & 98.3 & 77.2 & 98.9 \\
\hline Non-respiratory (49) & 5 & 1 & 0 & 43 & 85.7 & 100.0 & 100.0 & 97.7 \\
\hline Quality control (13) & 10 & 0 & 0 & 3 & 100.0 & 100.0 & 100.0 & 100.0 \\
\hline
\end{tabular}

$\star$ Sixty eight were contaminated cultures.

${ }^{\star}$ Nine were positive by culture for non-tuberculous mycobacteria; six were culture negative.

$\mathrm{NPV}$, negative predictive value; PPV, positive predictive value.

cultures were sent to the Mycobacterial Reference Unit for confirmation, speciation, and antimicrobial susceptibility testing. A specimen was considered positive if culture yielded $M$ tuberculosis as confirmed at the reference unit, or if the patient's clinical history, including chest roentgenograms and clinical presentation, was sufficiently indicative of tuberculosis to warrant empirical antituberculosis treatment. ${ }^{14}$

The sensitivity, specificity, positive predictive value (PPV), and negative predictive value (NPV) of the LCx assay were calculated and compared with smear and culture results and relevant clinical data. The prognostic value of sequential LCx assays together with smear and culture investigations were monitored in a cohort of 15 patients receiving antituberculosis treatment over a period of one to nine months.

The costs of introducing the LCx assay into a routine diagnostic laboratory were calculated using the WELCAN unit system. ${ }^{16}$

\section{STATISTICAL ANALYSIS}

Sensitivity, specificity, PPV, and NPV were calculated by standard methods. The $\chi^{2}$ test was used to compare rates.

\section{Results}

In all, 2120 specimens (1700 sputum, 358 bronchial aspirates/lavages, 49 non-pulmonary specimens, and 13 quality control samples) yielded $131 M$ tuberculosis positive cultures $(6.2 \%)$ from $48(4.1 \%)$ patients out of 1161 investigated. Nine patients were diagnosed with non-tuberculous mycobacteria (NTM), including three $M$ avium complex isolates, three $M$ xenopi, one $M$. kansasii, and two unspeciated environmental mycobacteria. All quality control specimens $(n=13)$ yielded the correct test result.

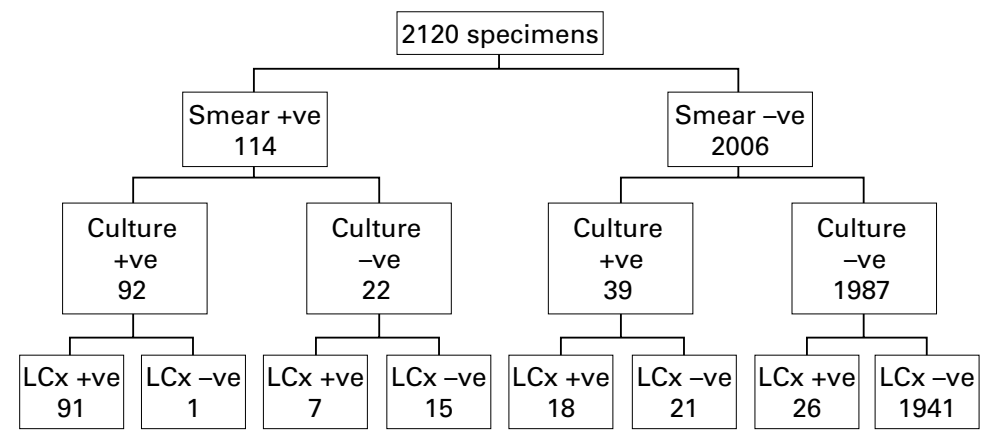

Figure 1 Evaluation of the ligase chain reaction ( $L C x)$ assay in culture confirmed tuberculosis.
The performance of the LCx assay, evaluated using culture confirmed tuberculosis as the gold standard, is shown in table 1 and represented schematically in fig 1 . One hundred and fourteen specimens were smear positive (5.4\%), 92 of which $(80.7 \%)$ were culture positive for $M$ tuberculosis. Seven specimens were smear positive and LCx positive but culture negative for $M$ tuberculosis. All seven patients were treated for tuberculosis on clinical grounds.

Nine of 15 samples that were smear positive, LCx negative, and culture negative for $M$ tuberculosis yielded NTM. The remaining six samples in this group were negative for tuberculosis by clinical evaluation and were not treated with antimycobacterial drugs. The sensitivity of the assay was higher in smear positive samples than smear negative samples $(98.9 \% v$ $65 \%$; table 1).

The performance of the LCx assay with clinically resolved cases of tuberculosis (culture plus clinical and radiological data) is shown in table 2 and represented schematically in fig 2 . The overall sensitivity was $88 \%$, with significant differences in sensitivity between the smear positive and smear negative specimens (99\% v 76\%). All samples that were LCx positive were either from culture confirmed cases of tuberculosis or clinically resolved cases of tuberculosis. There were no false positives.

Results of the LCx assay, microscopy, and culture for $M$ tuberculosis were compared in parallel using clinical criteria for the diagnosis of tuberculosis as the reference standard. Table 3 shows these data. The LCx assay was $88.2 \%$ sensitive and $100 \%$ specific. The sensitivity of auramine staining was significantly lower at $60.4 \%(\mathrm{p}<0.01)$.

Fifteen patients had a series of tests done after initial presentation and the initiation of treatment. There was only one patient (JK) with a sustained false negative result, which on repeated assay was culture positive for $M$ tuberculosis but remained LCx negative. Table 4 presents the effect of treatment on test results over a period of two to nine months. In nine of 15 patients, the LCx result remained positive after treatment, and in four patients the LCx remained positive after cultures were negative. A brief case study is presented for each of these patients.

For specimens requiring decontamination and digestion each assay was costed at 15 WELCAN units costing $£ 22.25(\sim 36.00) /$ 
Table 2 Evaluation of the ligase chain reaction ( $L C x$ ) assay in clinically resolved cases of Mycobacterium tuberculosis infection (culture results and clinical data)

\begin{tabular}{|c|c|c|c|c|c|c|c|c|}
\hline \multirow[b]{2}{*}{ Specimens $(n=2120)$} & \multicolumn{2}{|c|}{$\begin{array}{l}\text { No. resolved as positive for } \\
\text { M tuberculosis }(n=164)\end{array}$} & \multicolumn{2}{|c|}{$\begin{array}{l}\text { No. resolved as negative for } \\
\text { M tuberculosis }(n=1956)\end{array}$} & \multirow[b]{2}{*}{$\begin{array}{l}\text { Sensitivity } \\
(\%)\end{array}$} & \multirow[b]{2}{*}{$\begin{array}{l}\text { Specificity } \\
(\%)\end{array}$} & \multirow[b]{2}{*}{$\begin{array}{l}P P V \\
(\%)\end{array}$} & \multirow[b]{2}{*}{$\begin{array}{l}N P V \\
(\%)\end{array}$} \\
\hline & $\begin{array}{l}\text { LCx } \\
\text { positive }\end{array}$ & $\begin{array}{l}\text { LCx } \\
\text { negative }\end{array}$ & $\begin{array}{l}L C x \\
\text { positive }\end{array}$ & $\begin{array}{l}\text { LCx } \\
\text { negative }\end{array}$ & & & & \\
\hline All (2120) & 142 & 22 & 0 & $1956^{\star}$ & 88.2 & 100.0 & 100.0 & 98.9 \\
\hline Smear positive (114) & 98 & 1 & 0 & $15^{\star \star}$ & 99.0 & 100.0 & 100.0 & 93.8 \\
\hline Smear negative (2006) & 44 & 21 & 0 & 1941 & 75.6 & 100.0 & 100.0 & 98.9 \\
\hline Respiratory (2058) & 124 & 22 & 0 & $1913^{\star}$ & 86.9 & 100.0 & 100.0 & 98.9 \\
\hline Non-respiratory (49) & 5 & 1 & 0 & 43 & 85.7 & 100.0 & 100.0 & 97.7 \\
\hline Quality control (13) & 10 & 0 & 0 & 3 & 100.0 & 100.0 & 100.0 & 100.0 \\
\hline
\end{tabular}

${ }^{\star}$ Sixty eight were contaminated cultures.

$\star \star$ Nine were positive by culture for non-tuberculous mycobacteria; six were culture negative.

$\mathrm{NPV}$, negative predictive value; PPV, positive predictive value.

test; for sterile fluids the assay was worth 10 WELCAN units at $£ 10.68(\sim \$ 16.00) /$ test. The total cost of this test was $£ 46658.25$ ( $\sim$ $70000.00)$ over 13 months or approximately $£ 42000 /$ year.

\section{Discussion}

The rapid and reliable detection of $M$ tuberculosis in clinical specimens is an important aspect of the management of the disease. Fluorochrome staining and microscopy is simple and rapid but requires a skilled microscopist, is tedious to perform if the work load is heavy, and does not lend itself to automation. Apart from being relatively insensitive, it cannot differentiate between $M$ tuberculosis and NTM. Culture is specific and more sensitive but takes weeks. The LCx assay is a semiautomated assay; the initial sample preparation and DNA extraction is performed manually and constitutes the major portion of assay time.

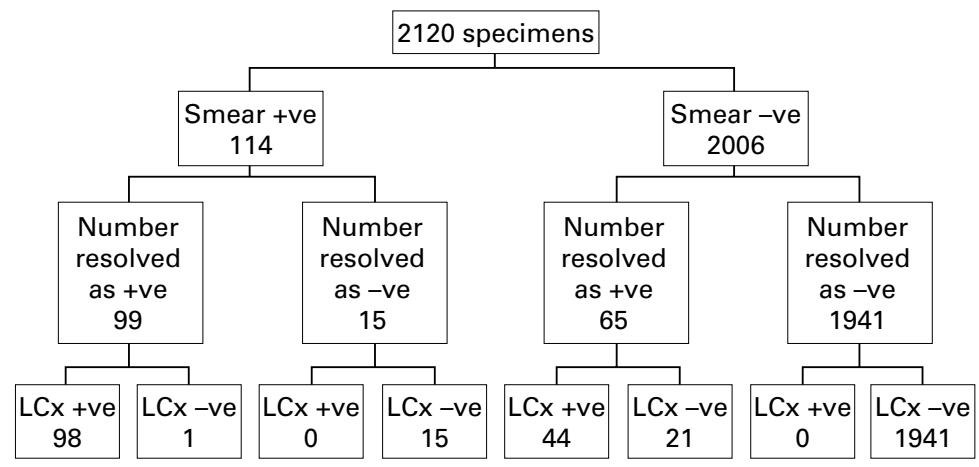

Figure 2 Evaluation of the ligase chain reaction ( $L C x$ ) assay in clinically resolved cases of tuberculosis (culture results and clinical data).

Table 3 Performance of the ligase chain reaction ( $L C x$ ) assay compared with culture and microscopy in clinically resolved cases of tuberculosis (TB)

\begin{tabular}{|c|c|c|c|c|c|c|}
\hline \multirow[b]{2}{*}{$\begin{array}{l}\text { Test method and } \\
\text { outcome (no.) }{ }^{\star}\end{array}$} & \multicolumn{2}{|c|}{ Clinical diagnosis } & \multirow[b]{2}{*}{$\begin{array}{l}\text { Sensitivity } \\
(\%)\end{array}$} & \multirow[b]{2}{*}{$\begin{array}{l}\text { Specificity } \\
(\%)\end{array}$} & \multirow[b]{2}{*}{$\begin{array}{l}P P V \\
(\%)\end{array}$} & \multirow[b]{2}{*}{$\begin{array}{l}N P V \\
(\%)\end{array}$} \\
\hline & $\begin{array}{l}T B+ \\
(n=164)\end{array}$ & $\begin{array}{l}\text { TB- } \\
(n=1956)\end{array}$ & & & & \\
\hline \multicolumn{7}{|l|}{$L C x$ assay } \\
\hline Positive (142) & 142 & 0 & $88.2^{\star \star}$ & 100.00 & 100.00 & 98.9 \\
\hline Negative (1978) & 22 & 1956 & & & & \\
\hline \multicolumn{7}{|l|}{ Auramine staining } \\
\hline Positive (114) & 99 & 15 & 60.4 & 99.2 & 91.6 & 96.8 \\
\hline Negative (2006) & 65 & 1941 & & & & \\
\hline \multicolumn{7}{|l|}{ Culture } \\
\hline Positive (131) & 131 & 0 & $83.2^{\star \star}$ & 100.00 & 100.00 & 98.3 \\
\hline Negative (1989) & 33 & 1956 & & & & \\
\hline
\end{tabular}

${ }^{\star}$ Includes specimens subject to repeat testing after diagnosis and initiation of treatment.

${ }^{\star \star} \mathrm{LCx}$ is more sensitive than culture because patients on treatment who become culture negative remain $\mathrm{LCx}$ positive.

NPV, negative predictive value; PPV, positive predictive value.
The amplification, hybridisation, and detection steps are automated and the assay can be completed from receipt of sample to reporting of results in five to six hours, making same day reporting feasible. Although the test is not validated for non-respiratory specimens, we included a selection of these specimens in our study. We also used the assay to confirm early culture growth from solid media, with $100 \%$ sensitivity and specificity compared with reference methods of identification.

The sensitivity, specificity, and ease of use of the LCx assay has been corroborated by many studies. ${ }^{13} 141819$ Most of the studies evaluating the performance of the LCx assay have focused on patients with a high suspicion of tuberculosis; this has a bearing on the sensitivity, specificity, and the PPV of the test. ${ }^{1420}$ In our study, all respiratory and a selection of nonrespiratory specimens that were submitted to the mycobacteriology laboratory were examined serially. The test results are hence a more realistic representation of performance in a relatively high risk area for tuberculosis. The LCx yielded no false positives in our hands; other workers have reported false positives, suggesting contamination in the laboratory as a possible explanation. ${ }^{14}$

In all, we documented 16 of 164 patients with clinically suspicious tuberculosis in whom, at initial presentation, the LCx assay was the earliest test method to yield a positive result. In seven patients, smear examination was consistently negative; in the remainder, smear positivity appeared on repeat testing some weeks later. These patients would have experienced delays in diagnosis had it not been for the LCx assay; however, treatment was not delayed because clinically the index of suspicion was high. In six patients, the LCx assay was positive and the culture consistently failed to grow the organism or was contaminated throughout the course of their treatment. In only one patient did the LCx assay hasten both the diagnosis and the onset of treatment. One patient's specimen was consistently false negative even on repeat testing (JK; table 4).

As in the case of smear and culture analyses it is recommended that more than one sample should be tested at initial presentation to allow sufficient accuracy in the detection of $M$ tuberculosis DNA. ${ }^{14}$

From table 4 , it is apparent that the LCx assay remains positive after the institution of 


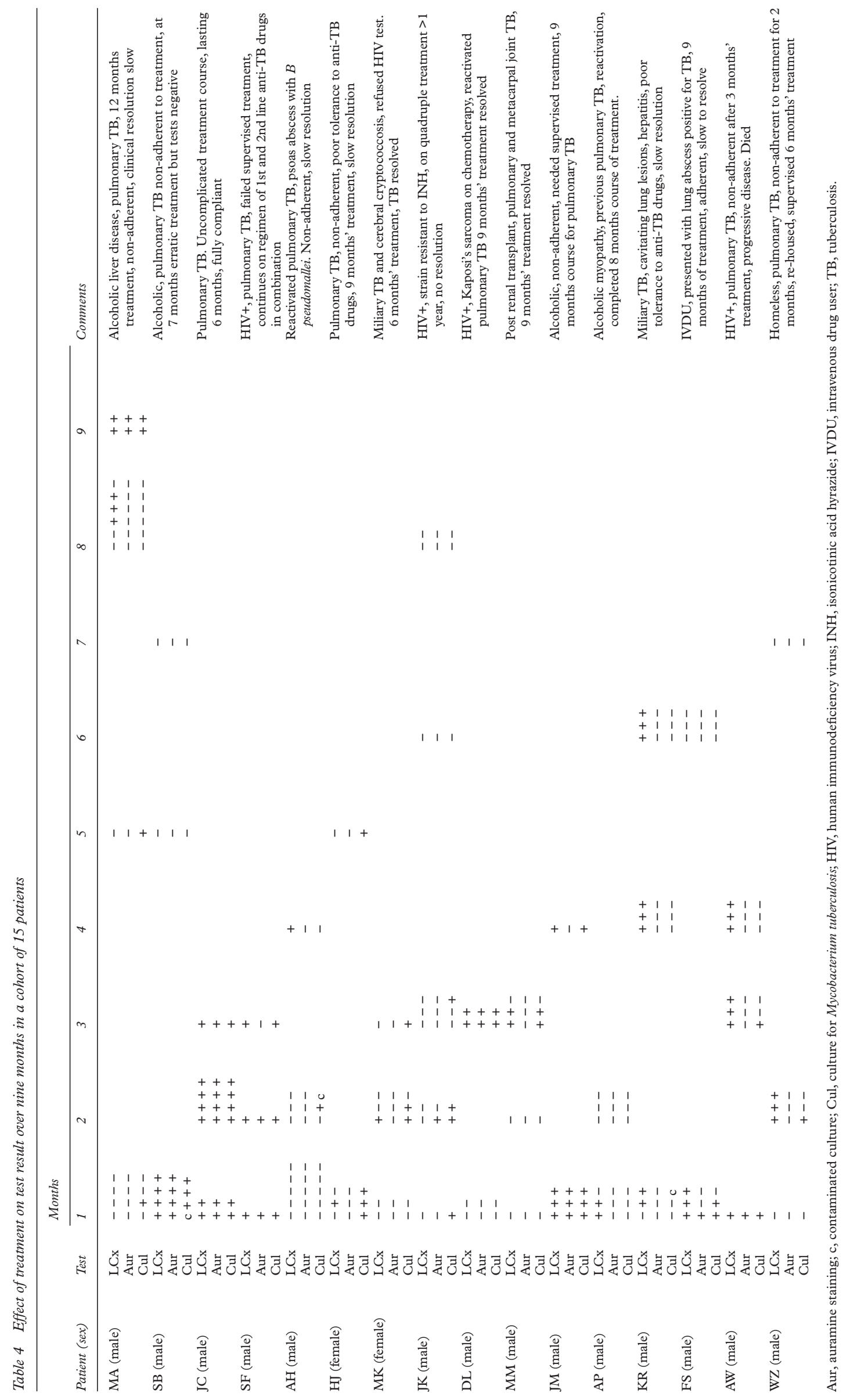

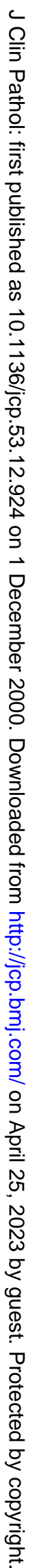


treatment, often when smears and later cultures are negative. Among the patients who were slow to resolve or succumbed to their illness, an equal number were LCx positive (MA, $\mathrm{SF}, \mathrm{KR}, \mathrm{AW}$ ) as were $\mathrm{LCx}$ negative ( $\mathrm{SB}, \mathrm{AH}$, JK, FS) on serial testing. AW and $\mathrm{SF}$ remained LCx positive long after the study period. Therefore, it is recommended that the LCx is not used to monitor adherence to treatment or as a prognostic test.

The obvious advantage of the LCx assay is the rapid differentiation of tuberculosis from cases of NTM in smear positive samples. The LCx did not crossreact with any of the NTM, both in patient specimens and in quality control samples. Given the absence of false positives it is apparent that an LCx positive specimen would strongly support the diagnosis of tuberculosis in clinically suspicious cases.

The cost of the assay, over 13 months unrestricted use, was $£ 46658.25(\sim 70000)$ or approximately $£ 42500$ /year. As with all semiautomated tests, the more tests that are done on a daily basis the greater the cost benefit, both in terms of the laboratory budget and the cost implications in patient care. If the assay is only performed on stored samples once or twice a week, it would undermine the definite advantage of speed in achieving a diagnosis. The investment in an additional assay for the rapid diagnosis of tuberculosis is considerable and should be guided by the local rate of positive cultures for $M$ tuberculosis.

In conclusion, the LCx assay, as an initial diagnostic test, has $>80 \%$ sensitivity and $100 \%$ specificity, making it a useful although expensive adjunct to confirm clinical suspicion of tuberculosis. LCx on non-respiratory specimens compares well with smear and culture in detecting $M$ tuberculosis. The assay is not useful as a prognostic test and should not be used to evaluate adherence to treatment. It is particularly useful when rapid differentiation between $M$ tuberculosis and NTM is needed. It has been used with $100 \%$ accuracy to confirm $M$ tuberculosis from growth on solid media. Because the onset of treatment was influenced by the test in only one patient, the cost benefit of the assay remains questionable.

We thank Dr P Nye and her team in the respiratory laboratory at UCLH for incorporating the LCx assay into the routine examination of specimens for mycobacterial disease and for her meticulous records of laboratory results. Thanks are also due to Dr R Miller for access to his patient data. The study was supported entirely by the UCLH microbiology consumables budget.

1 Kochi A. The global tuberculosis situation and the new control strategy of the World Health Organisation. Tubercle 1991;72:1-6.

2 Bloom BR, Murray CJL. Tuberculosis: commentary on a reemergent killer. Science 1992;257:1055-64.

3 Bhatti N, Law MR, Morris JK, et al. Increasing incidence of tuberculosis in England and Wales: a study of the likely causes. BMF 1995;310:963-6.

4 Hayward A. Tuberculosis control in London-the need for change. A report for the Thames Regional Directors of Public Health. A discussion document. London: NHS Executive, 1998

5 Hayward AC, Watson JM. Tuberculosis in England and Wales 1982-1993; notifications exceeded predictions. Commun Dis Report CDR Suppl 1995;5:RR29-33.

6 Rodrigues LC, Smith PG. Tuberculosis in developing countries and methods for its control. Trans $R$ Soc Trop Med Hyg 1990;84:739-44.

7 Malasky C, Jordan T, Potulski F, et al. Occupational tuberculous infections among pulmonary physicians in training. Am Rev Respir Dis 1990; 142:505-7.

8 Beck-Sague C, Dooley SW, Hutton MD, et al. Hospital out break of multidrug resistant Mycobacterium tuberculosis infections. Factors in transmission to staff and HIVinfected patients. FAMA 1992;268:1280-6.

9 Anonymous. Outbreak of hospital acquired multidrug resistant tuberculosis Commun Dis Rep CDR Suppl 1995;5: 161.

10 Wilson SM, McNerney R, Nye PM, et al. Progress toward a simplified polymerase chain reaction and its application to diagnosis of tuberculosis. F Clin Microbiol 1993;31:776-82.

11 Wilson SM, Nava E, Morales A, et al. Simplification of the polymerase chain reaction for detection of Mycobacterium tuberculosis in the tropics. Trans R Soc Trop Med Hyg 1993; 87:177-80.

12 Kent L, McHugh TD, Billington O, et al. Demonstration of homology between IS 6110 of Mycobacterium tuberculosis and DNAs of other Mycobacterium spp. $\mathcal{F}$ Clin Microbiol 1995;33:2290-3.

13 Ausina V, Gamboa F, Gazapo E, et al. Evaluation of the semi-automated Abbott LCX Mycobacterium tuberculosis assay for direct detection of Mycobacterium tuberculosis in assay for direct detection of Mycobacterium tuberculosis in 2002 .

14 Garrino MG, Glupczynski Y, Degraux J, et al. Evaluation of the Abbott LCX Mycobacterium tuberculosis assay for direct detection of Mycobacterium tuberculosis complex in human samples. F Clin Microbiol 1999;37:229-32.

15 Bahl MR. Prevention and control of tuberculosis. April Report. London: Camden and Islington Health Authority. 1998.

16 Department of Health: Welsh Office, Welcan UK. Workload measurement system for pathology. Cardiff: HMSO, 1990.

17 Stokes EJ, Ridgway GL, Wren MWD. Investigation of chronic infections. In: Clinical microbiology, 7 th ed. London: Edward Arnold, 1993:173-83.

18 Tortoli E, Lavinia F, Simonetti MT. Evaluation of commercial ligase chain reaction kit (Abbott LCx) for direct detection of Mycobacterium tuberculosis in pulmonary and extra-pulmonary specimens. F Clin Microbiol 1997;35: 2424-6.

19 Gamboa F, Dominguez J, Padilla E, et al. Rapid diagnosis of extra-pulmonary tuberculosis by ligase chain reaction amplification. f Clin Microbiol 1998;36:1324-9.

20 Ieven M, Goossens H. Relevance of nucleic acid amplification techniques for diagnosis of respiratory tract infections in the clinical laboratory. Clin Microbiol Rev 1997;10:242in the 